Research, Society and Development, v. 9, n.1, e88911679, 2020

(CC BY 4.0) | ISSN 2525-3409 | DOI: http://dx.doi.org/10.33448/rsd-v9i1.1679

\title{
O sistema $Q$-Acadêmico e os desafios de docentes e discentes para a interação online
}

The Q-Academic system and the challenges of teachers and students for online interaction

El sistema Q-Academic y los desafíos de los profesores y estudiantes para la interacción en línea

Recebido: 17/09/2019 | Revisado: 24/09/2019 |Aceito: 30/09/2019 | Publicado: 04/10/2019

\section{Claudia Lucia Landgraf Valerio}

ORCID: https://orcid.org/0000-0001-8222-1293

Instituto Federal de Mato Grosso, Brasil

E-mail: claudia.valerio@cba.ifmt.edu.br

\section{Resumo}

Com o avanço da tecnologia, o surgimento de espaços interativos online está cada vez mais presente no cotidiano das pessoas. Com a escola não poderia ser diferente. Verificamos distintos softwares usados na educação com o propósito de facilitar a interação da comunidade escolar, entretanto ainda não é muito expressivo o número de estudos que contemplem essa temática. Considerando esse contexto, nossa proposta visa discutir os desafios da interação entre professores e alunos via $Q$-Acadêmico no IFMT. Para sustentar nossas discussões, partimos das premissas de formação de professores de Nóvoa (2007) e Paris et all (1984) e dos estudos de formação de professores para contexto digital de Coscarelli (2007) e Xavier (2003). A metodologia, de caráter qualitativo, contou com duas fases: na primeira aplicamos um questionário, com questões abertas e fechadas, em professores e alunos, sobre o uso das ferramentas Mensagem e Material de Aula do QAcadêmico, e, na segunda, procedemos à análise dos resultados coletados. Esperamos, com esse estudo, tecer o perfil de interação efetivado entre docentes e discentes e verificar os desafios de uso dessas ferramentas do Q-Acadêmico, contribuindo, assim, para que a comunidade escolar do IFMT se aproprie dos recursos disponíveis neste ambiente, aprimorando o processo de ensino-aprendizagem no IFMT.

Palavras-chave: Formação de professor; Ensino; Tecnologia.

\section{Abstract}


With the advancement of technology, the emergence of interactive online spaces is increasingly present in people's daily lives. With school could not be different. We verified different software used in education with the purpose of facilitating the interaction of the school community, however the number of studies that contemplate this theme is not very expressive yet. Considering this context, our proposal aims to discuss the challenges of interaction between teachers and students via Q-Academic at IFMT. To support our discussions, we start from the teacher training assumptions of Nóvoa (2007) and Paris et all (1984) and the teacher education studies for digital context by Coscarelli (2007) and Xavier (2003). The qualitative methodology had two phases: in the first one we applied a questionnaire with open and closed questions, in teachers and students, about the use of the Q-Academic Message and Classroom tools, and, in the second, we proceeded to the analysis of the collected results. With this study, we hope to weave the interaction profile between teachers and students and to verify the challenges of using these Q-Academic tools, thus contributing for the IFMT school community to take advantage of the resources available in this environment, improving the teaching-learning process at IFMT.

Keywords: Teacher training; Teaching; Technology.

\section{Resumen}

Con el avance de la tecnología, la aparición de espacios interactivos en línea está cada vez más presente en la vida cotidiana de las personas. Con la escuela no podría ser diferente. Verificamos diferentes programas utilizados en educación con el propósito de facilitar la interacción de la comunidad escolar, sin embargo, el número de estudios que contemplan este tema aún no es muy expresivo. Teniendo en cuenta este contexto, nuestra propuesta tiene como objetivo discutir los desafíos de la interacción entre profesores y estudiantes a través de Q-Academic en IFMT. Para apoyar nuestras discusiones, partimos de los supuestos de capacitación docente de Nóvoa (2007) y Paris et all (1984) y los estudios de formación docente para el contexto digital de Coscarelli (2007) y Xavier (2003). La metodología cualitativa tenía dos fases: en la primera, aplicamos un cuestionario con preguntas abiertas y cerradas, en profesores y estudiantes, sobre el uso de las herramientas Q-Academic Message y Classroom, y, en la segunda, continuamos al análisis de los resultados recopilados. Con este estudio, esperamos tejer el perfil de interacción entre maestros y estudiantes y verificar los desafíos de usar estas herramientas Q-Academic, contribuyendo así para que la comunidad escolar IFMT aproveche los recursos disponibles en este entorno, mejorando el proceso de enseñanza-aprendizaje en IFMT. 
Palabras-clave: Formación del profesorado; Enseñanza; Tecnología.

\section{Introdução}

O homem, desde o seu nascimento, está inserido em um meio social, a família, e estabelece relações com o outro pela linguagem. Assim, como ser histórico e social, constituise em sua interação com o outro nas mais diferentes esferas, dentre elas a escola. (VYGOTSKY, 1978). O surgimento da Internet modificou e ampliou a relação entre as pessoas, apresentando novas possibilidades com o uso desse canal interativo.

Nesse sentido, a maneira de agir, pensar e de interagir de todos, empresas, governos, instituições públicas e privadas foi alterada, evidenciando uma diversidade de oportunidades na utilização desse novo canal de comunicação. Sob essa ótica, o processo de interação nas escolas também sofreu mudanças, transformando o espaço escolar e promovendo novas formas de comunicação/interação.

Dentre essas novas formas de interação, destacamos as efetivadas no IFMT via o software de gestão acadêmica - Q-Acadêmico - desenvolvido pela empresa Qualidata Soluções em Informática Ltda. Entretanto e, diante da demanda de cursos oferecidos pelo IFMT e do número de pessoas envolvidas nesse processo, perguntamo-nos se a interação feita no IFMT mediada pelo Q-Acadêmico tem conseguido dar maior publicidade aos resultados, históricos de aluno, além de oportunizar aos educadores poderem, via Q-Acadêmico, disponibilizar informações para seus alunos? Para responder a esses questionamentos nos propomos a desenvolvemos esta pesquisa, com o intuito de tecer um perfil de uso e de interação entre os atores (educadores e alunos) envolvidos no processo de comunicação com uso do Q-Acadêmico.

Nessa plataforma, há disponíveis vários recursos e considerando as possibilidades de interação via Q-Acadêmico de docentes e discentes, destacamos, para esse estudo, as ferramentas Material de Aula e Mensagem pela fragilidade aparente em seu uso, situação que nos levou a propor esta pesquisa.

As perguntas tiveram como foco o conhecimento, por parte dos envolvidos, dessas ferramentas disponibilizadas pelo Q-Acadêmico, além de verificar quais são as outras que são utilizadas para interação de educadores com seus alunos, buscando, assim, conhecer as dificuldades e as possibilidades de interação no cotidiano escolar. Os resultados obtidos com essa pesquisa mostram os pontos que precisam ser reorganizados e reajustados para garantir interação com os usuários. 
A concepção de formação de professores aqui adotada segue os preceitos do professor reflexivo de Nóvoa (2007), com uma proposta de formação desenvolvida em serviço, reflexiva e processual, que não busca um produto pronto, mas a criação de um movimento cuja dinâmica se estabelece quando refletimos na ação e sobre a ação. Nessa perspectiva, os docentes em formação têm a oportunidade de vivenciar diferentes propostas pedagógicas, inclusive com uso de tecnologias, de transpô-la para a prática pedagógica, de socializar os resultados obtidos com os alunos e de refletir sobre os seus próprios resultados e os de seus colegas de estudo, realimentando a formação de cada professor do grupo.

Sendo assim, não se trata de uma formação com o objetivo de efetivar uma prática somente no futuro, mas também no presente, para a ação imediata do educador. Trata-se de uma concepção de formação de professores, que subsidia as discussões sobre a inclusão digital de professores em formação.

A profissionalização do educador está em constante construção e transformação e, de acordo com Nóvoa (2007), esse é um processo que se constitui de Adesão, Ação e Autoconsciência (AAA). O autor fez um estudo da profissionalização docente com base em algumas reflexões sobre as escolhas profissionais e a interferência das características pessoais do profissional sobre as suas ações pedagógicas. Ao destacar a importância de se considerar os três AAA que sustentam esse processo de profissionalização, o autor explica que a Adesão acontece quando o professor adere a determinados valores e princípios, a $\boldsymbol{A} c ̧ \tilde{a} o$ efetiva-se quando o educador faz escolhas profissionais que norteiam todo o seu trabalho e a Autoconsciência desenvolve-se por meio do processo de reflexão, o que leva a mudanças pedagógicas. Desse modo, tudo se decide por meio do pensamento reflexivo do professor sobre a sua própria ação, que vai promover mudanças e inovações pedagógicas.

Essa postura reflexiva requer do educador uma capacidade de metacognição constante que, de acordo com Paris et all (1984), consolida-se em três formas de conhecimento: declarativo (aquele que o educador assume ter); procedimental (sobre o processo pedagógico) e condicional (construído na interação com o outro e que define quando agir). Ao ponderarmos sobre esses conhecimentos no processo de formação de professores, retomamos o perfil do profissional reflexivo, que compreende sua prática e apropria-se de sua posição como sujeito de seu fazer pedagógico.

Paralelo a esse processo de reflexão sobre sua prática pedagógica há a inserção das tecnologias como instrumento de apoio a suas atividades profissionais cotidianas. Desta forma, o educador, assim como seu aluno, encontra-se em um constante processo de letramento digital e, de acordo com Coscarelli (2007), momentos de formação dos professores 
são necessários para que a informática se instaure como tecnologia educacional.

Nessa mesma esteira do letramento digital docente, Xavier (2003) explicita que o educador não precisa ser um "expert" em computação, porém necessita saber buscar informação e saber usar esses conhecimentos com eficiência em suas atividades pedagógicas.

Para que o letramento digital, de educadores e de discentes, possa ser implementado na escola, não se pode ignorar a necessidade de uma formação que ultrapasse o mero uso técnico das tecnologias de informação e comunicação. Com essa apropriação do uso das tecnologias disponíveis na escola, tanto o trabalho pedagógico quanto a interação entre professores e alunos mediado pela tecnologia, promoverá efetivamente um processo de ensino e aprendizagem de qualidade.

Neste sentido, o objetivo desta pesquisa é propor uma discussão sobre os desafios da interação entre professores e alunos via $Q$-Acadêmico, considerando que este sistema se configura como uma ferramenta oficial de interação no IFMT.

\section{Metodologia}

Esta pesquisa apresenta um caráter qualitativo. De acordo com (SCHMIDT-GODOY, 1995) existem três tipos de pesquisa qualitativa: o Estudo de caso; a Etnografia e a Pesquisa Documental. Dos três tipos explicitados, utilizamos o Estudo de Caso, descrevendo e avaliando, através dos resultados obtidos, os desafios e as possibilidades de interação entre professores e alunos do IFMT via Q-Acadêmico.

Como sujeito de pesquisa, contamos com a colaboração de educadores e discentes do IFMT Campus Cuiabá - Cel. Octayde Jorge da Silva. Para o desenvolvimento da pesquisa optamos por duas fases: na primeira, aplicamos um questionário com questões fechadas e aberta tanto em educadores quanto nos alunos e, na segunda, procedemos à análise dos resultados coletados. Os questionários aplicados aos docentes foram elaborados pela ferramenta Formulários Google e distribuídos para o email de todos os docentes do Campus. Já com relação aos alunos, a aplicação do questionário aconteceu de forma presencial no Campus, com alunos de diferentes cursos de Ensino Médio Integrado.

Buscamos perceber como é a interação com o uso das ferramentas Material de Aula e Mensagem do Q-Acadêmico e, quando não são utilizadas, quais são as justificativas e outros recursos empregados para promover a comunicação de educadores e alunos.

\section{Resultados}


Research, Society and Development, v. 9, n.1, e88911679, 2020

(CC BY 4.0) | ISSN 2525-3409 | DOI: http://dx.doi.org/10.33448/rsd-v9i1.1679

Atualmente, o Q-Acadêmico dispõe de ferramentas para auxiliar a interação aluno e educador, porém ainda pouco utilizadas. Veremos, a seguir, o que pensam educadores e alunos sobre o processo de interação via as ferramentas Mensagem e Material de Aluno.

Inicialmente, buscamos traçar o perfil dos educadores participantes da pesquisa por Departamento. Observamos que houve participação semelhantes nos departamentos do Campus, conforme apresentado no gráfico 1:

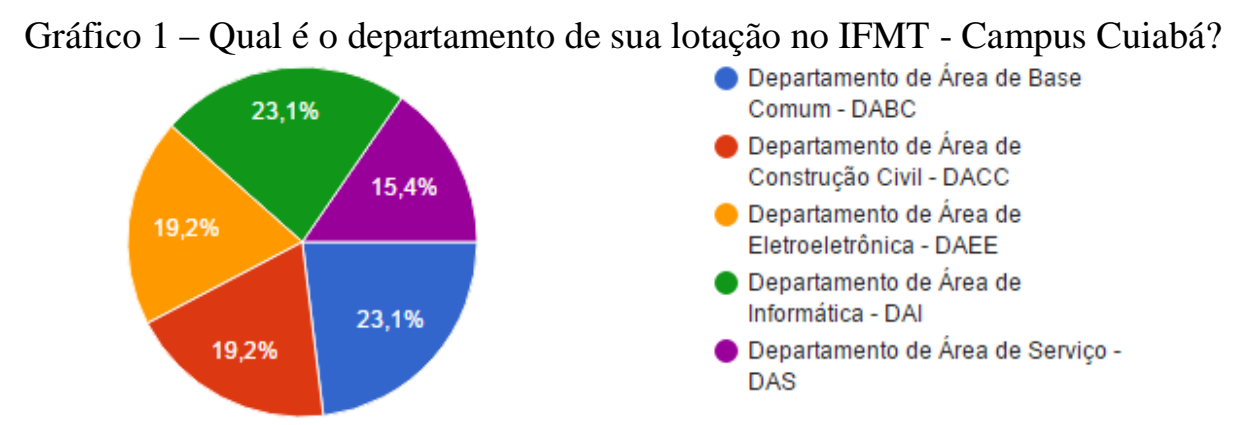

Em seguida, procuramos saber se os educadores têm conhecimento sobre as ferramentas Material de Aula ou Mensagem do Q-Acadêmico.

Gráfico 2 - Você conhece a ferramenta Material de Aula ou Mensagem do Q-Acadêmico?

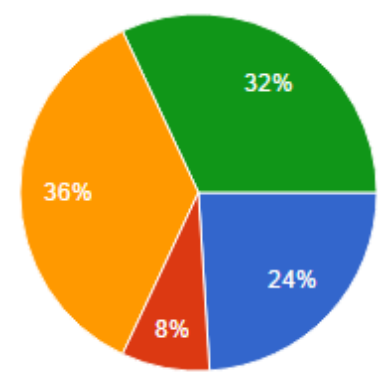

SIM - conheço somente a ferramenta Material de Aula;

SIM - conheço somente a ferramenta Mensagem;

SIM - conheço as duas ferramentas; NÃO.

Além do resultado apresentado no gráfico 2, verificamos que para os educadores o desconhecimento e a falta de rotina na utilização destas ferramentas gera o afastamento do QAcadêmico para este fim:

"Não utilizo porque esqueço dessas ferramentas, acho mais usual usar pastas na nuvem para compartilhar material com os alunos. Mas vou tentar utiliza-las" (Professor 2);

"Não uso por não ter conhecimento e desconhecer a ferramenta" (Professor 4);

“Primeiramente, nem sempre o Q-Academico está online - por diversas vezes ele ficou indisponível. Assim sendo, prefiro usar o email institucional para o atendimento aos alunos (recebimento e correção de atividades), bem como envio de material didático" (Professor 3) 
Research, Society and Development, v. 9, n.1, e88911679, 2020

(CC BY 4.0) | ISSN 2525-3409 | DOI: http://dx.doi.org/10.33448/rsd-v9i1.1679

"Falta de familiaridade com o ambiente do software." (Professor 1)

Considerando o pouco uso destas ferramentas, averiguamos quais são efetivamente utilizadas pelos educadores para envio de material de estudo para os alunos.

Gráfico 3 - Qual ou quais das ferramentas abaixo você utiliza para o envio de materiais utilizados em sala de aula?



Avaliando os resultados do gráfico 3, constatamos que o e-mail é a ferramenta mais utilizada pelos educadores. Constatamos que, para os educadores dos diferentes Departamentos, o limite no tamanho do arquivo, o layout da página, a falta de treinamento e o reconhecimento e a disposição por parte dos alunos para uso do Q-Acadêmico apresentam-se como complicadores para seu uso:

"Pouco espaço para envio de material didático, que, no meu caso, há necessidade de envios de arquivos mais robustos. Em relação, as mensagens, tentei utilizá-las algumas vezes, mas talvez por não ser muito usual entre a comunidade escolar acabei deixando de lado" (Professor 1)

"A interface não amigável, pouco espaço de memória, indisposição dos alunos em usá-lo, falta de conhecimento de detalhes na utilização, nunca nos deram um treinamento adequado" (Professor 2)

"Não uso muito por serem limitadas e não terem os recursos da plataforma Moodle, como envio de tarefas na forma de arquivos, por parte dos alunos" (Professor 3)

"Quando comecei a trabalhar no campus Cuiabá (2013/2), usei o recurso do Material de Aula, mas os alunos não acompanhavam. Percebi que usam um e-mail de turma e se comunicam mais por ele, e aderi a este recurso" (Professor 4)

Para os professores, estes são os fatores que comprometem o bom uso do QAcadêmico, promovendo o uso frequente de outras formas de interação como o e-mail de turma e de outras plataformas de ensino como o Moodle e AulaLegal.net que são ferramentas nas quais o educador disponibiliza os materiais podendo ser organizados em pastas ou facilitando uma boa interface para o aluno. 
Research, Society and Development, v. 9, n.1, e88911679, 2020

(CC BY 4.0) | ISSN 2525-3409 | DOI: http://dx.doi.org/10.33448/rsd-v9i1.1679

A dificuldade de alguns alunos em ter acesso à internet, para alguns professores, pode comprometer o seu trabalho pedagógico:

"Acho mais prático as formas que utilizo (pen-drive), pois, nem todos os alunos tem acesso a internet, mesmo nos dias atuais" (Professor 2)

Nesse contexto, a utilização do pen-drive apresentou-se como alternativa para algumas situações por ser uma forma segura e rápida de compartilhar os documentos utilizados em sala de aula.

É notório que por falta de conhecimento sobre as ferramentas citadas o educador fica impossibilitado de usá-las corretamente. Isto se deve à falta de uma formação continua considerando que não são todos que tem uma boa integração com espaços online. Esse contexto acaba promovendo o uso de outras ferramentas por parte dos próprios educadores, contribuindo para que o aluno busque se adaptar a essa utilização.

Para Nóvoa (2007), o professor reflexivo compreende sua condição e procura melhorá-la. Assim, podemos constatar que os educadores, sujeitos desta pesquisa, encontramse no processo de Adesão pois ele adere a determinados valores e princípios, no caso a algumas ferramentas disponibilizadas online, mas ainda não superaram a etapa da $\boldsymbol{A} c ̧ \tilde{a} o$ uma vez que fazem escolhas que norteiam todo o seu trabalho, mas suas escolhas são feitas a partir de um lugar seguro, limitando-se a usar os recursos que conhecem, sem explorar novas alternativas como as ferramentas Material de Aula e Mensagem do Q-Acadêmico.

Para que o uso destas ferramentas se torne parte do seu cotidiano pedagógico, uma postura metacognitiva (PARIS et all, 1984) se faz necessária pois é partir de reflexão da sua prática e dos recursos disponíveis que o processo de letramento digital se consolidará.

$\mathrm{Na}$ análise dos resultados obtidos, a partir dos elementos fornecidos pelos alunos, pudemos observar proximidades com relação a postura de educadores frente ao sistema. Quando os discentes são questionados sobre o conhecimento das ferramentas, encontramos o seguinte resultado:

Gráfico 4 - Você conhece a ferramenta Mensagem ou Material de Aula do Q-Acadêmico? 


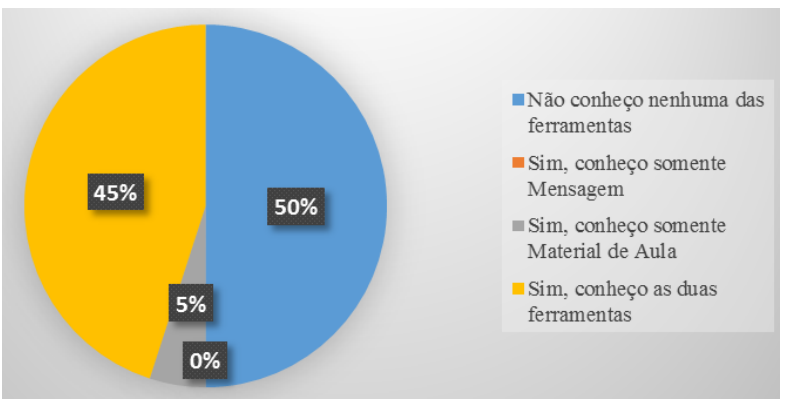

No gráfico 4 percebe-se que 50\% dos alunos entrevistados na pesquisa não conhecem nem a ferramenta Material de Aula e nem a ferramenta Mensagem e 45\% deles conhecem as duas ferramentas. Não há porcentagem de alunos que conhecem somente a ferramenta Mensagem e apenas 5\% conhecem somente a ferramenta Material de Aula.

Diante disso, verificamos quais as ferramentas os alunos utilizam do Q-Acadêmico. Os resultados são apresentados no gráfico 5:

Gráfico 5 - Quais são as ferramentas que você utiliza no Q-Acadêmico?

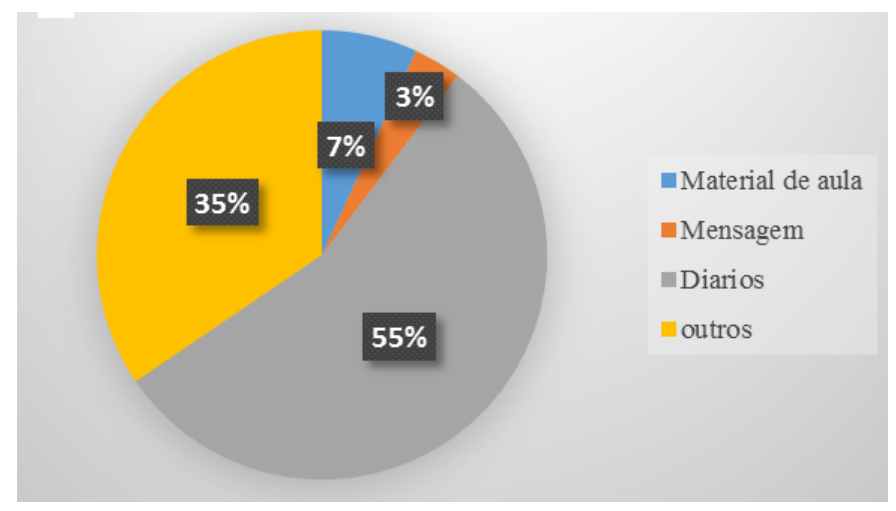

Ao observar o gráfico 5 é possível perceber que grande parte dos alunos (55\%) utilizam a ferramenta Diário e menor grupo (35\%) utilizam outras, 35\% utilizam outras ferramentas. Quanto as ferramentas foco desta pesquisa, apenas 7\% utilizam o recurso de Material de Aula e 3\% dos alunos entrevistados utilizam a ferramenta Mensagem.

É possível compreender que a maioria dos alunos utiliza o diário, pois é a ferramenta que usam para ver as notas. A comunicação não ocorre diretamente por meio desta opção visto que ela não serve para uma troca de materiais ou mensagens pois, para os alunos, ela é somente para a visualização das notas de provas, conceito de todos os bimestres, número de faltas e percentual de presença. Assim, a interação se efetiva de forma parcial quando considerado o Q-Acadêmico.

Ao serem questionados sobre o uso das ferramentas verificamos o seguinte resultado: 
Gráfico 6 - Você utiliza as ferramentas Mensagem ou Material de Aula do Q-Acadêmico?

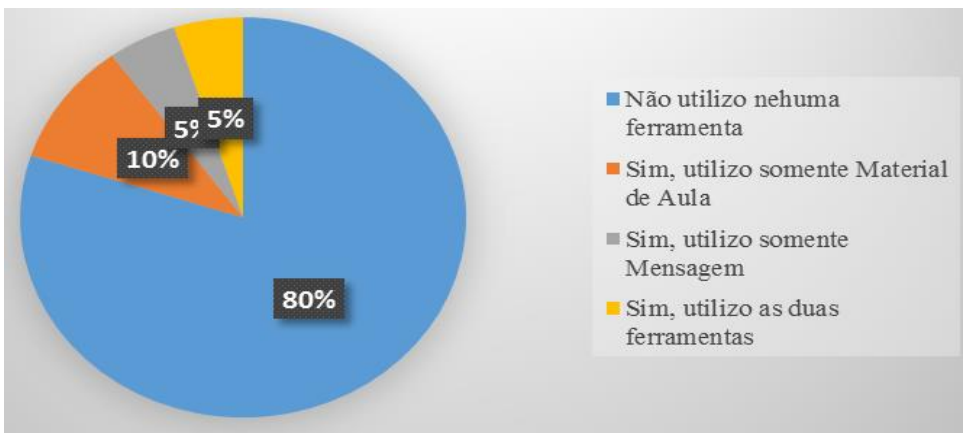

Comparando os resultados dos gráficos 4 e 6, observamos que, apesar de parte dos alunos entrevistados (45\%) conhecerem as duas ferramentas, apenas 5\% utilizam a ferramenta Mensagem e 5\% a ferramenta Material de Aula. Uma maioria significativa (80\%) não utilizam nenhuma das duas ferramentas enquanto apenas $10 \%$ dos estudantes usam somente Material de Aula e 5\% utilizam somente Mensagem.

Ao examinarmos quais a ferramentas são utilizadas para troca de materiais e informações, temos:

Gráfico 7 - Para troca de materiais e informações, que outras ferramentas você utiliza?

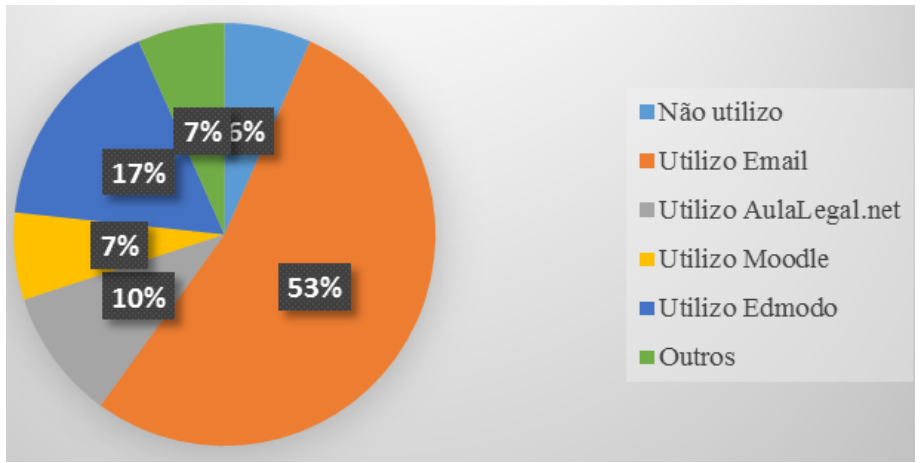

Como evidenciado no gráfico 7, o e-mail é a ferramenta mais utilizada para troca de dados entre os professores e os alunos, em seguida com 17\% vem o Edmodo. Assim como 
10\% dos entrevistados utilizam o Aulalegal.net. Empatados com 7\% vem Moodle e a opção outras ferramentas que, segundo os entrevistados, se concretiza no uso do pen-drive.

Para que os discentes façam uso das ferramentas Material de aula e Mensagem é necessário que os educadores a utilizem no processo de interação com seus alunos. Para Coscarelli (2007), o professor precisa estar disposto a mudanças para que ela se efetive em seu cotidiano escolar. Neste sentido, Xavier (2003) expõe que o professor não precisa conhecer profundamente a internet e seus recursos, mas precisa conhecer o suficiente para utilizar o que tem disponível a seu favor.

Diante do exposto, salientamos a necessidade de uma formação contínua que possibilite ao educador conhecer os recursos disponíveis no Q-Academico para, numa postura reflexiva, verificar o uso produtivo das ferramentas Mensagem e Material de Aula durante o processo pedagógico com seus alunos

\section{CONSIDERAÇÕES FINAIS}

O que se pode avaliar, de modo geral, é que a interação virtual entre educadores e alunos ainda não ocorre a contento, pois há uma grande da parcela de educadores que apontam insatisfação na utilização das ferramentas Material de Aula e Mensagem disponíveis pelo Q-Acadêmico no IFMT.

A partir dos questionários aplicados nesta pesquisa, observamos que é necessário o aprofundamento de estudos sobre essas importantes ferramentas, que talvez não esteja sendo utilizada da melhor forma por questões de falta de conhecimento dos usuários e das limitações do próprio sistema.

Todos os problemas apresentados pelos educadores prejudicam o uso dessas ferramentas. Por outro lado, não se pode ignorar que alguns professores não têm familiaridade com ambientes virtuais, não estimulando o uso entre os estudantes. Uma nova etapa de formação continuada, tanto para inclusão digital quanto para o uso das ferramentas de interação do Q-Acadêmico, apresenta-se como uma necessidade para educadores e para os próprios alunos que, de acordo com os professores, preferem utilizar outros recursos.

Após a análise do material coletado com os alunos, é possível perceber que a interação entre o professor e o aluno por meio do Q-Acadêmico é pouco expressiva. Constatamos que a ferramenta mais utilizada para troca de matérias é o e-mail, pois de acordo com os alunos, esta é uma forma mais eficiente de comunicação. 
Research, Society and Development, v. 9, n.1, e88911679, 2020

(CC BY 4.0) | ISSN 2525-3409 | DOI: http://dx.doi.org/10.33448/rsd-v9i1.1679

Sendo assim, para grande parte dos discentes o Q-Acadêmico serve apenas para ver as notas. Dessa forma, constatamos que ambos, professores e alunos, preferem não utilizar o QAcadêmico ora por não gostarem do site, ora por achá-lo ineficiente ou por não o conhecerem como seria necessário para efetivar a interação por via desta plataforma digital.

Esta discussão não se esgota neste trabalho visto que a interação online na escola é um desafio constante para educadores, discentes e gestores para que o processo de ensino e aprendizagem possa ser fortalecido no ambiente escolar.

\section{Referências}

Coscarelli, C. V. (2007) Alfabetização e letramento digital. In: ; RIBEIRO, A. E.

(Orgs.) Letramento digital: aspectos sociais e possibilidades pedagógicas. 2. ed. Belo Horizonte: Ceale; Autêntica.

Nóvoa, A.(2007) Os professores e as histórias da sua vida. In: (Org.) Vidas de professores. 3. ed. Porto: Porto Editora.

Paris, S. G.; Cross, D. R.; Lipson, M. Y. (1984) Informed strategies for learning: a program to improve children's reading awareness and comprehension. Journal of Educational Psychology, 76 (6), 1239-125. Disponível em: https://www.researchgate.net/publication/232541174_Informed_Strategies_for_Learning_A Program_to_Improve_Children's_Reading_Awareness_and_Comprehension Acesso em: 5 jun. 2018.

Schmidt-Godoy, A. (1995) Introdução à pesquisa qualitativa e suas possibilidades. Revista de Administração de Empresas, Rio de Janeiro, v. 35, n.2, p. 57-63.

Vygotsky, L. S. (1978) A formação social da mente - o desenvolvimento dos processos psicológicos. 4. Ed. Trad. José Cipolla Neto, Luís Silveira Menna Barreto, Solange Castro Afeche. São Paulo: Martins fontes.

Xavier, A. C. S. (2003) Letramento digital e ensino. Disponível em: http://www.ufpe.br/nehte/artigos/Letramento\%20digital\%20e\%20ensino.pdf . Acesso em: 10 abr. 2018. 
Porcentagem de contribuição do autor no manuscrito

Claudia Lucia Landgraf Valerio - 100\% 